\title{
Difference in the In-Hospital Mortality of Unstable Angina Pectoris between Men and Women
}

\author{
Luiz Carlos Santana Passos, Antonio Alberto Lopes, Úrsula Costa, Nelson Lobo, Alvaro Rabelo Jr \\ Salvador, BA - Brazil
}

\begin{abstract}
Purpose - To assess differences in the in-hospital mortality $(H M)$ rate between men and women with unstable angina pectoris (UA) according to age, depression of the ST segment, history of previous acute myocardial infarction (AMI), and risk factors for coronary heart disease.
\end{abstract}

Methods - From October 96 to March 98, 261 patients with UA were selected. Logistic regression models were developed to adjust the association between sex and HM for possible influence of covariables, such as hypertension, diabetes mellitus, dyslipidemia, sedentary lifestyle, smoking, and familial history of early coronary heart disease.

Results - HM due to UA was approximately three times higher in women $(9.3 \%$; 12/129) than in men $(3.0 \%$; 4/132) accounting for a relative risk of $3.07 ; 95 \%$ confidence interval $(C I)=1.02-9.27$. In logistic regression models, the association between sex and death was not significantly altered when the following parameters were considered: age, depression of the ST segment, history of previous AMI and risk factors for coronary heart disease. The nonadjusted and adjusted odds ratio $(O R)$ for the distinct covariables were 3.28 (CI 95\%=1.03-10.45) and $3.14(C I=95 \%=0.88-11.20)$, respectively.

Conclusion - Similarly to AMI, HM in UA is higher in women than in men. Age, risk factors for coronary heart disease, and depression of the ST segment in the electrocardiogram on patients' admission to the hospital did not significantly influence the association between sex and death.

Key words: unstable angina pectoris, women, in-hospital mortality

Fundação Bahiana de Cardiologia, Hospital Universitário Prof. Edgar Santos e Universidade Federal da Bahia - Salvador

Mailing address: Luiz Carlos Santana Passos - Rua Waldemar Falcão, 889/1701 - 40295-001 - Salvador, BA - Brazil
Numerous studies have consistently shown that mortality in acute myocardial infarction (AMI) is higher in women than in men ${ }^{1-9}$. There is evidence that some factors related to the female gender, such as advanced age at the time of hospital admission, a higher frequency of heart failure, a larger interval between symptom onset and hospital admission, and lesser access to medical care partially explain the higher mortality in women with AMI. In regard to unstable angina pectoris (UA), there are few studies comparing the prognosis between men and women, which is particularly amazing considering the large number of hospital admissions due to UA at cardiology services ${ }^{10}$. In addition, the risk of death during hospital admission for this group of patients can reach $5 \%$ to $10 \%{ }^{11}$. These points motivated the present study, whose main purpose was to assess the possible association between sex and in-hospital mortality (HM) due to UA in a cardiology service in the city of Salvador in the Brazilian state of Bahia.

\section{Methods}

All patients in this study ( $\mathrm{n}=261)$ were admitted to the Cardiology and Cardiovascular Surgery Unit of the Fundação Bahiana de Cardiologia (FBC), at the Hospital Universitário Prof. Edgar Santos, of the Federal University of Bahia. This hospital has a 24-hour emergency unit and is a referral service for the entire state of Bahia. Patients were prospectively and consecutively selected at the time of hospital admission to the Coronary Unit, from October 96 to March 98. Patients with one of the following characteristics were excluded from the study: those with elevated levels of CKMB in the first 12 hours after admission (these patients were considered to have evolving AMI); those patients remaining in the hospital for less than 48 hours free from events because the period of observation was considered too short; and those with diagnosis on hospital discharge different from UA because they did not have angiographic documentation of coronary heart disease (CHD) or objective evidence of spontaneous or provoked ischemia.

Data collected were from the hospital phase of the UA, 
which is defined as precordial pain compatible with myocardial ischemia at rest (with or without electrocardiographic alteration) or progressive angina (i.e., alterations in the frequency, duration or intensity of the symptoms in the last two months). The operational definitions of the risk factors for coronary heart disease are those used in the II Consenso Brasileiro de Dislipidemia (II Brazilian Consensus of Dyslipidemia) ${ }^{12}$. Clinical and laboratory data were obtained on a daily basis during the hospital stay, using a standard form. There was no interference by the investigators in the clinical management of the patients.

The following parameters were treated as potentially confounding or intermediate in the association between sex and UA: age, class of UA (Braunwald classification), electrocardiographic alterations on hospital admission, and risk factors for coronary heart disease (systemic hypertension (SH), diabetes mellitus, dyslipidemia, sedentary lifestyle, smoking, familial history of early CHD). The chi-square test and the Student's $t$ test for independent samples were used to evaluate the statistical significance of the differences between proportions and means, respectively, after verifying if the data agreed with the premises for these tests. In the nonadjusted analysis, the relative risk (RR) was used as a measure of association between sex and HM. In the adjusted analysis by logistic regression, the odds ratio (OR) was used as a measure of association, because this measure and its confidence intervals (CI) are easily determined through the antilogarithm of the regression coefficient. It is important to note, however, that in this study the OR could be used as an approximate estimate of the RR because the frequency of death was smaller than $10 \%$.

The need for logistic models stratified for different levels of independent variables was assessed through statistical significance of the coefficients of interaction between the variable sex and each of the other covariables. As none of the interactions was statistically significant ( $p>0.1$ ), the predictive variables were included altogether in the models. The analyses were performed through the SPSS software, version 6 for Windows. To assess the statistical significance of the association between sex and death, the null hypothesis was RR or OR equal to 1 .

\section{Results}

During the period of study, $40 \%$ (520/1282) of the 1,282 admissions, were due to acute coronary syndrome (UA or AMI) and 50.2\% (261/520) of these patients were diagnosed as having UA (table I). The percentages of men (50.6\%) and women were similar. The means of age were also similar for both sexes (men: 61.1 \pm 12.2 years vs women: $62.2 \pm 12.5$ years; $\mathrm{p}=0.35)$. Women, however, showed more depression of the ST segment than men (28.7\% vs $11.4 \%$; $\mathrm{p}<0.001)$. Most of the patients, $93.8 \%$ of the women vs $87.1 \%$ of the men were Braunwald class III (i.e., pain at rest in the last 48 hours). At admission, $51.5 \%$ of the men were using two or more antianginal medications (Braunwald class IIIB2) while only $36.4 \%$ of the women were doing so $(\mathrm{p}=0.01)$. The mean time of stay in the coronary unit was approximately $2.7 \pm 2.3$ days; this was similar between men (2.6 \pm 1.6 days $)$ and

\begin{tabular}{|c|c|c|c|}
\hline Characteristics & $\begin{array}{l}\text { Women } \\
\mathrm{n}=129\end{array}$ & $\begin{array}{c}\text { Men } \\
\mathrm{n}=132\end{array}$ & $\begin{array}{c}\text { Value of } \\
\text { P }\end{array}$ \\
\hline Age (years) & $62.6 \pm 12.5$ & $61.1 \pm 12.2$ & 0.35 \\
\hline \multicolumn{4}{|l|}{ Race } \\
\hline White & $52(40.3 \%)$ & $59(44.7 \%)$ & 0.47 \\
\hline Black and Mullato & $77(59.7 \%)$ & $73(55.3 \%)$ & 0.47 \\
\hline \multicolumn{4}{|l|}{ ECG alterations } \\
\hline Normal & $27(20.9 \%)$ & $31(23.5 \%)$ & 0.62 \\
\hline Depression of the ST segment & $37(28.7 \%)$ & $15(11.4 \%)$ & 0.0005 \\
\hline Other alterations of ST-T & $65(50.4 \%)$ & $86(65.1 \%)$ & 0.02 \\
\hline Class III (Braunwald) & $120(93 \%)$ & $115(87.1 \%)$ & 0.11 \\
\hline Previous use of at least antianginal medications & $68(51.5 \%)$ & $47(36.4 \%)$ & 0.01 \\
\hline \multicolumn{4}{|l|}{ Risk factors for coronary atherosclerotic disease } \\
\hline Hypertension & $113(87.3 \%)$ & $92(69.7 \%)$ & 0.0004 \\
\hline Diabetes mellitus & $46(35.7 \%)$ & $39(29.5 \%)$ & 0.29 \\
\hline Dyslipidemia & $72(55.8 \%)$ & $48(36.4 \%)$ & 0.002 \\
\hline Familial history & $41(31.8 \%)$ & $28(21.2 \%)$ & 0.05 \\
\hline Sedentary lifestyle & $88(68.2 \%)$ & $76(57.6 \%)$ & 0.08 \\
\hline Smoking & $23(17.8 \%)$ & $49(37.1 \%)$ & 0.0005 \\
\hline 3 or more risk factors & $85(65.9 \%)$ & $67(50.8 \%)$ & 0.01 \\
\hline \multicolumn{4}{|c|}{ Evidence of previous coronary atherosclerotic disease } \\
\hline Previous stroke & $11(8.5 \%)$ & $13(9.8 \%)$ & 0.71 \\
\hline Previous AMI & $31(24 \%)$ & $71(53.8 \%)$ & $<0.001$ \\
\hline Previous MR/PTCA* & $24(18.6 \%)$ & $35(26.5 \%)$ & 0.13 \\
\hline
\end{tabular}


women (2.7 \pm 2.8 days). The same occurred with hospital stay, $7.8 \pm 7.9$ days, $7.1 \pm 6.5$ days for men and $8.4 \pm 9.2$ days for women $(\mathrm{p}=0.13)$.

In regard to the risk factors for CHD, women had a higher prevalence of SH (87.3 vs $69.7 \%$; p<0.001) and dyslipidemia (55.4\% vs $36.4 \%$; $<<0.01)$. Smoking was more prevalent in men $(34.7 \%$ vs $19.0 \%$; $<<0.01)$. The percentage of patients with three or more risk factors for CHD was higher in women $(64.5 \%$ vs $50.4 \%$; $p=0.03)$; however, history of previous AMI was more common in men $(51.2 \%$ vs $23.1 \%$ ).

During hospitalization, there was no difference in treatment between men and women, including the use of acetylsalicylic acid, beta-blockers, nitrates (intravenous and oral) and heparin. Coronary angiography was performed in $60.2 \%(157 / 261)$ of the patients, $62.1 \%(82 / 132)$ of the men and $58.1 \%(75 / 129)$ of the women. Noncritical coronary lesions (lesion $<50 \%$ ) were more frequent in women $(30.7 \%$ vs $9.8 \%$; $<<0.01)$. Based on the coronary angiographic profile, women underwent myocardial revascularization less frequently than men $(20.9 \%$ vs $28.0 \%$; $<0.18)$.

Despite their small percentage of noncritical coronary lesions, women had an HM approximately three times higher than men $(\mathrm{RR}=3.07 ; \mathrm{CI} 95 \%=1.01-9.27 ; \mathrm{p}=0.035)$ (table II). In the logistic regression models, the association between sex and death was not significantly altered after considering the potential effects of age, of the depression of the ST segment, the risk factors for coronary heart disease, and history of previous AMI (table III). In the model with sex as the only independent variable $(\mathrm{OR}=3.28$; $\mathrm{CI} 95 \%=1.03$ $10.45 ; p=0.044)$, the OR was very similar to that in another model with depression of the ST segment, history of previous AMI and risk factors for coronary heart disease $(\mathrm{OR}=3.15$; $\mathrm{CI} 95 \%=0.88-11.23 ; \mathrm{p}=0.078)$. Consistent with the similarity of age between men and women, the inclusion of this variable in the logistic model almost did not alter the OR of the association between sex and HM $(\mathrm{OR}=3.14$; CI $95 \%=0.88-11.20 ; \mathrm{p}=0.077$ ).

All deaths occurring in this study were ascribed to cardiovascular disease and, for both men and women, - - of these deaths resulted from severe left ventricular failure. One death was related to cardiac rupture, two others to ventricular arrhythmia and two others were considered sudden cardiac death.

\begin{tabular}{|c|c|c|c|c|c|}
\hline & \multicolumn{2}{|c|}{ Death } & \multirow[b]{2}{*}{ Mortality } & RR & \multirow[b]{2}{*}{$\mathrm{p}$} \\
\hline & Yes & No & & & \\
\hline Female & 12 & 117 & $9.3 \%$ & $\begin{array}{c}3.07 \\
(1.02-9.27)\end{array}$ & 0.035 \\
\hline Male & 4 & 128 & $3.0 \%$ & & \\
\hline
\end{tabular}

\section{Discussion}

Unlike AMI, on which several studies are available, this is the first study comparing HM in men and women with UA treated in an usual clinical situation. The results support the possibility that, similarly to that which is observed for AMI, HM due to UA is higher among women than among men. It is important to note that the excess of risk of death for women remained almost unaltered after considering differences in age, history of previous AMI, depression of the ST segment and risk factors for coronary heart disease. The influence of hormonal factors, associated noncardiac comorbidities, such as hypothyroidism, obstructive pulmonary disease, anemia or coagulopathies, in the differences of mortality between the sexes could not be evaluated in this study. Evidence that these associated comorbidities may interfere with the prognosis of the CHD support their inclusion in further studies investigating differences in mortality between men and women with UA and other acute coronary syndromes ${ }^{10,13}$.

Despite the evidence that the treatment administered to women with AMI is more conservative than that administered to men in similar situations ${ }^{14,15}$, this study does not support the idea that the worse prognosis for women with UA relates to differences in the criteria for indication of pharmacological treatment, as well as coronary angiography or revascularization. In reality, the lower frequency of revascularization in women agrees with the better coronary artery anatomy in that group, as demonstrated by the results of the coronary angiography.

The intensity of coronary atherosclerosis does not seem to relate to a worse outcome of the UA among women, because the frequency of noncritical lesions (lesions $<50 \%$ ) was much higher in women than in men. This finding are consistent with those of other investigators ${ }^{16-18}$. The results of this study supports the development of further investigations, aiming to clarify whether prothrombotic mechanisms or even merely yet unidentified functional factors can explain the worse prognosis for women with UA ${ }^{19}$.

Discussing the findings of the present study, it is necessary to consider the results of the TIMI IIIB trial, the only study that compares prognoses of men and women with acute coronary syndrome. Unlike the present study, the TIMI IIIB trial was designed primarily for secondary analysis of a randomized clinical trial comparing two types of strategies for patients with UA and non Q wave AMI, who were eligible for thrombolytic therapy (r-TPA). Considering that women fulfill the criteria of eligibility for thrombolytic therapy less frequently than do men ${ }^{20}$, it is expected that in the TIMI IIIB trial there was a selection of female patients with a better prognosis than that observed in clinical practice. This can explain the conclusion of the authors of the TIMI IIIB trial that the in-hospital prognosis was similar between sexes. It is important to note, however, that analyzing the findings of the TIMI IIIB trial according to the type of treatment, it is estimated that in the group treated in a conservative way (revascularization only in the 


\begin{tabular}{|c|c|c|}
\hline & OR (CI 95\%)* & $\mathrm{P}$ \\
\hline Nonadjusted association & $3.28(1.03-10.45)$ & 0.044 \\
\hline Association adjusted for depression of the ST segment, history of previous AMI and risk factors for coronary heart disease & $3,15(0,88-11,23)$ & 0,078 \\
\hline Association adjusted for age, depression of the ST segment, history of previous AMI and risk factors for coronary heart disease & $3,14(0,88-11,20)$ & 0,077 \\
\hline
\end{tabular}

presence of ischemia), the risk of death for patients with UA or AMI without the Q wave was more than three times higher among women than among men.

An interesting finding of the present study and also of the TIMI IIIB trial is that women with UA had a higher mortality rate than do men, despite a less severe coronary atherosclerotic process in women by coronary angiography.

In conclusion, the present study is an evidence that women admitted to the coronary unit with the diagnosis of UA had a higher risk of death than did the men. The possible determinants of higher HM among women were not explored in this study; however, the results suggest that age, risk factors for coronary heart disease, depression of the ST segment and the intensity of the coronary atherosclerosis present were not enough to explain the worse prognosis for women. The finding that mortality due to UA is higher among women, although consistent with that which is observed in AMI should not yet be considered widely applicable, deserving, rather, further investigation in different place and under different clinical circumstances.

\section{References}

1. Greenland P, Reicher-Reiss H, Goudbourt U, Behar S, Israeli SPRINT investigators. In-hospital and 1-year mortality in 1.524 women after myocardial infarction. Circulation 1991; 83: 484-91.

2. Fiebach NH, Viscoli CM, Horwitz RJ. Differences between women and men in survival after myocardial infarction: biology or methodology? JAMA 1990; 263: 1092-6.

3. Dittrich H, Gilpin E, Nicod P, Cali G, Henning H, Ross J. Acute myocardial infarction in women:influence of gender on mortality and prognostic variables. Am J Cardiol 1988; 62: 1-7.

4. Maynard C,Litwin PE, Martin JS, Weaver WD. Gender differences in the treatment and outcomes of acute myocardial infarction-results from the Myocardial Infartion Triage and Intervention Registry. Arch Itern Med 1992; 152: 972-6.

5. Passos LC, Lopes AA, Souza CAM, et al. Preditores de mortalidade hospitalar na era trombolítica para o infarto agudo do miocárdio em Salvador(BA). Arq Bras Cardiol 1997; 68: 249-55.

6. Puletti M, Sunseri L, Curione M, Erba SM, Borgia C. Acute myocardial infarction: sex-related differences in prognosis. Am Heart J 1984; 108: 63-6.

7. Weaver WD, Harvey DW, Wilcox RG, et al. Gusto investigators. Comparisons of characteristics and outcomes among women and men with acute myocardial infarction treated with thrombolytic therapy. JAMA 1996; 275: 777-83.

8. Kostis JB, Wilson A, O'Dowd K and Midas Study Group. Sex differences in the management and long-term outcome of acute myocardial infarction. Circulation 1994; 90: 1715-32.

9. Malacrida R, Genone M, Maggioni AP, et al. A comparison of the early outcome of acute myocardial infarction in women and men. N Eng J Med 1998; 338: 8-14.

10. Hochman J, McCabe CH, Stone PS, et al. Outcome and profile of women and men presenting with acute coronary syndromes: A report from TIMI IIIB. J Am Coll Cardiol 1997; 30: 141-8.
11. Rizik DG, Healy S, Margulis A, et al. A new clinical classification for hospital prognosis of unstable angina pectoris. Am J Cardiol 1995; 75: 993-7.

12. Consenso Brasileiro de Dislipidemia: detecção, avaliação e tratamento (II). Arq Bras Cardiol 1996; 67: 109-28.

13. White HD, Barbash GI, Modan M, et al. After correcting for worse baseline characteristics, women treated with thrombolytic therapy for acute myocardial infarction have the same mortality and morbidity as men except for higher incidence of hemorragic stroke. Circulation 1993; 88: 2097-103.

14. Clarke W, Gray D, Keating NA, Hamptom JR. Do women with acute myocardial infartion receive the same treatment as men? Br Med J 1994; 309: 563.

15. Herholz H, Goff DC, Ramsey DJ, et al. Women and Mexican Americans receive fewer cardiovascular drugs following myocardial infarction than men and nonhispanic whites: the Corpus Christi Heart Project, 1988-1990. J Clin Epidemiol 1996; 49: 279-87.

16. William AE, Freman MR, Chisholm RJ, Patt NL, Armstrong PW. Angiographic morphology in unstable angina pectoris. Am J Cardiol 1988; 62: 1024-7.

17. Alison HW, Russel RO, Mantle JA, Kouchoukos NT, Moraski RE, Racley CE. Coronary anatomy and arteriography in patients with unstable angina pectoris. Am J Cardiol 1978; 41: 204-9.

18. Diver D, Bier JD, Ferreira PE et TIMI-IIIA Investigators. Clinical and arteriographic characterization of patients with unstable angina without critical coronary arterial narrowing (from the TIMI-IIIA trial). Am J Cardiol 1994; 74 : $531-7$.

19. Benamer $\mathrm{H}$, Prost $\mathrm{D}$, Bridey $\mathrm{F}$, et al. Gender difference in factor VII and activated factor VII leves in unstable angina. Thrombosis Haemostasis 1996; 75: 971-82.

20. Maynard C, Althose R, Cerqueira M, Olsulfka M, Kennedy JW. Underutilization of trombolytic therapy in elegible women with acute myocardial infarction. Am J Cardiol 1991; 68: 529-30. 